\title{
Multi-Institutional Clinical Study
}

National Cancer Institute

\section{Source}

National Cancer Institute. Multi-Institutional Clinical Study. NCI Thesaurus. Code C142611.

A clinical study that is being conducted at multiple locations. 